\title{
Fish out of water: consumers' unfamiliarity with the appearance of commercial fish species
}

\author{
Marine Cusa ${ }^{1,2}$ (1) $\cdot$ Luara Falcão $^{1,3}$ (1) Joseph De Jesus ${ }^{2} \cdot$ Cristina Biolatti $^{4} \cdot$ Lancelot Blondeel $^{5} \cdot$ Fiona S. A. Bracken ${ }^{6}$. \\ Lisa Devriese $^{7} \cdot$ Sandra Garcés-Pastor $^{8} \cdot$ Styliani Minoudi ${ }^{9} \cdot$ Chrysoula Gubili $^{10} \oplus$. Pier Luigi Acutis ${ }^{4}$. \\ Stefano Mariani ${ }^{1}$ (i)
}

Received: 2 September 2020 / Accepted: 15 February 2021 / Published online: 15 March 2021

(c) Crown 2021

\begin{abstract}
Seafood labels play an increasingly key role in assisting consumers in purchasing processed and featureless fish products, and in encouraging sustainable fishing and aquaculture practices. While informed purchasing choices are typically influenced by traceability and labelling awareness, they also depend on the consumers' ability to identify and discriminate the fish species available on the market, which to date remains notably unexplored. We asked 720 people across six European countries to identify pictures of six fish species commonly sold in Europe. We reveal that European consumers have a poor understanding of the appearance of the fish they consume (overall 30\% correct identification), with British consumers performing the poorest and Spanish ones doing best. We noted cultural association with some species, whereby the most regionally consumed fish are more easily recognized. We argue that despite recent improvements in technological solutions, stakeholder dialogue, and policy implementation, seafood market transparency will remain open to malpractice until consumers restore connection with their food.
\end{abstract}

Keywords Sustainable fishing $\cdot$ Seafood traceability $\cdot$ Mislabeling $\cdot$ Environmental awareness $\cdot$ Food literacy $\cdot$ Marine conservation

\section{Introduction}

Seafood product substitution and lack of transparency in the supply chain open the door to the trade of endangered species, to unsustainable aquaculture and fishing practices

Handled by Patrik JG Henriksson, Post-doc Stockholms Universitet Stockholm Resilience Centre Kräftriket 2B Stockholm, Sweden.

Marine Cusa

M.L.Cusa@1jmu.ac.uk

1 School of Biological and Environmental Sciences, Liverpool John Moores University, Liverpool, UK

2 School of Science, Engineering and Environment, University of Salford, Salford, UK

3 Grupo de Investigação Biológica Integrada, CEABIO/ICB, Federal University of Pará, Belém, PA, Brazil

4 Istituto Zooprofilattico Sperimentale del Piemonte, Liguria e Valle d'Aosta Via Bologna 148, 10154 Torino, Italy

5 Flanders Research Institute for Agriculture, Fisheries and Food, Ankerstraat 1, 8400 Ostend, Belgium and to the depletion of stocks, while exposing consumers to health and safety risks and enabling fraudulent business (Cohen 1997; Jacquet and Pauly 2007; Fields et al. 2020). While neglect or genuine mistakes are sometimes the root cause of seafood mislabeling, deliberate fraudulent behaviour driven by the appeal of economic gain or by the trade of products derived from illegal, unreported, and unregulated (IUU) fishing will also result in instances of mislabeling (Cawthorn and Mariani 2017; Donlan and Luque

6 Area 52 Research Group, School of Biology and Environmental Science/Earth Institute, University College Dublin, Dublin, Ireland

7 VLIZ-Flanders Marine Institute, InnovOcean site, Wandelaarkaai 7, 8400 Ostend, Belgium

8 UiT-The Arctic University of Norway, Troms $\varnothing$ Museum, N-9037 Troms $\varnothing$, Norway

9 School of Biology, Aristotle University of Thessaloniki, 54124 Thessaloniki, Greece

10 Hellenic Agricultural Organisation-DEMETER, Fisheries Research Institute, Nea Peramos, 64007 Kavala, Greece 
a
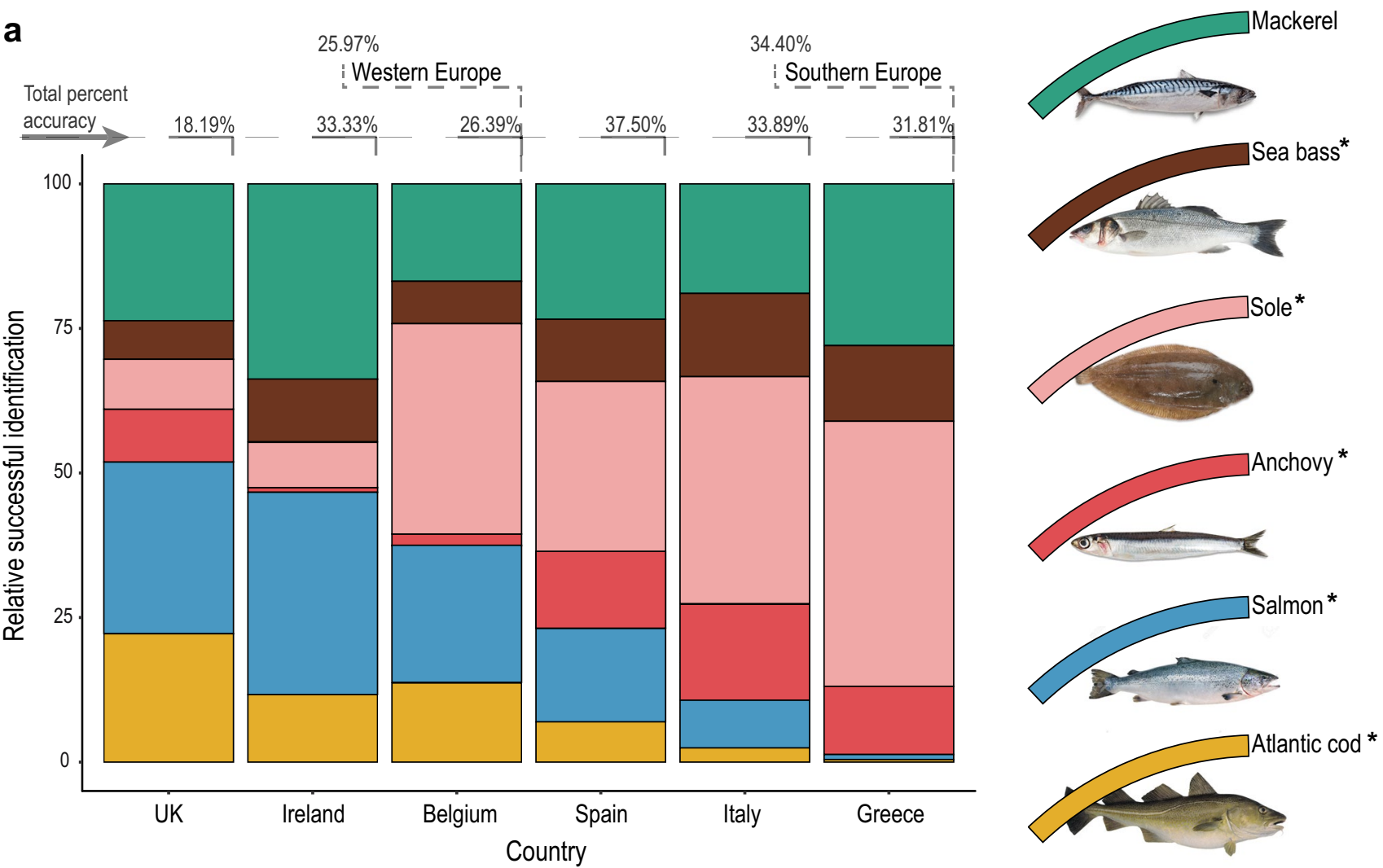

b

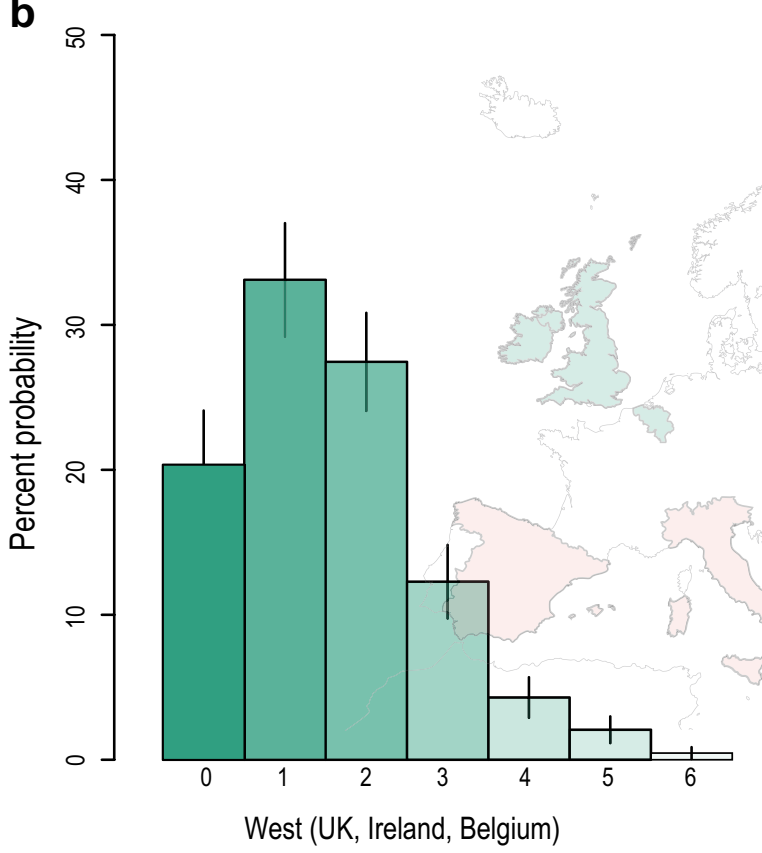

Number of correct answers

2019; Calosso et al. 2020). The advent of DNA-based tools has shed light on the worldwide scale and pervasiveness of seafood mislabeling, in some cases escalating tangible change through improved governance and media attention
(Mariani et al. 2014). This is particularly true for Europe, where the mislabeling of certain species has been shown to substantially decrease as a response to public awareness and improved legislation (Mariani et al. 2015). Yet, it 
4Fig. 1 a Relative successful identification of each of the six fish species for each of the six countries. The stacked bar graph only depicts correct identifications and the total percent accuracy is shown above the stacked bars for each country and for both regions. The bar graph segments represent how much percentage can be attributed to each species out of the total number of correctly identified fish. For instance, out of $31.81 \%$ identification success in Greece, about half is due to sole. Consumers' correct answers were compared between regions for each species independently, and the star (*) indicates that identification accuracy for that species was significantly different between Western and Southern European regions as tested via categorical chi-squared tests. The photos presented to the participants are depicted in the legend along with the species common name. b Consumers probability of falling into categories 0 to $6(0=$ zero fish correctly identified and $6=$ six fish correctly identified) for northern countries (United Kingdom, Ireland, and Belgium) and southern countries (Spain, Italy, and Greece) as predicted from a cumulative link model $(\mathrm{clm})$ fitted values. The error bars correspond to the \pm 1.96 standard error for the mean prediction

remains unclear whether these rapid improvements can be sustained over the longer term. Consumers' knowledge on fisheries resources has been credited with a role in fostering seafood sustainability (Olson et al. 2014), but virtually nothing is known about consumers' familiarity with the fish they eat, a concept that we hereby term 'seafood literacy'.

Though there is no set definition for the concept of food literacy, the majority of experts view it as the knowledge required for consumers to make informed purchasing and feeding choices with regards to personal health, environmental impact, and ethical standards (Bellotti 2010; Vidgen and Gallegos 2014; Perry et al. 2017). Species literacy, a recent concept coined by Hooykaas et al. (2019), encompasses one's knowledge on specific species including the ability to recognize species visually. In fact, the sole ability to identify and name species has previously been associated with greater levels of affinity, respect, and appreciation (Schlegel and Rupf 2010; Mohneke et al. 2016). Given the great diversity of species on the seafood market and their diverging life histories, ecological roles, and conservation status, consumer ability to recognize species is a particularly relevant and empowering aspect of seafood literacy (Gaviglio et al. 2014). Fish products are too often considered as a homogenous commodity, grouped under the term 'Fish' (Gaviglio et al. 2014), or frequently aggregated in generic categories or 'umbrella terms' (Griffiths et al. 2013; Cawthorn et al. 2018). The use of hypernyms in the seafood industry or deliberate mislabeling practices can hide the trade of vulnerable species, or of species prone to IUU fishing (Cawthorn and Mariani 2017; Calosso et al. 2020) and can lead to the oblivious consumption of fish from poorly managed stocks (Kroetz et al. 2020). A limited ability to recognize and distinguish between species can potentially result in a general lack of concern for marine biodiversity (Balmford et al. 2002; Schlegel and Rupf 2010) thereby encouraging fraudulent behaviour and allowing damaging practices, such as fish substitution, to persist.

Globalisation and technological advances, such as improvements in freezing abilities, have also changed our relationship with food and have led to increased commoditization of seafood (Anderson et al. 2018). A 350\% rise in seafood demand since the mid-1970s (FAO 2017) and the resulting increase in seafood commoditization is responsible for a decreasing demand in species-specific products and for a growing tolerance in the substitution of species within key groups (Anderson et al. 2018) such as white fish, tuna, salmon, etc. These factors bear a tremendous impact on consumption habits and have emotionally and physically detached urban consumers from the source of the food they purchase (Vileisis 2008; Bellotti 2010).

Given the importance of consumer knowledge in an increasingly complex seafood market, studies have sought to identify how consumers react to labelling and traceability tools (Altintzoglou and Nøstvold 2014; Rodriguez and Dopico 2020; Vitale et al. 2020), yet to our knowledge, none has quantitatively assessed buyers' familiarity with the appearance of the fish they purchase. In this study, we first assessed consumers' response accuracy with respect to the identification of commonly consumed fish species and explored how this might differ between countries and/ or regions. We then explored regional patterns of inaccuracy with a focus on the richness and diversity of wrong answers. We conducted this evaluation of consumers' ability to identify widely available seafood species in urban centers of six European countries. This allowed us to encompass comprehensive cultural range and urban seafood consumption habits, in 'Southern' and 'Western' European countries, as defined by the EU Commission map (EUMOFA 2017), with the former typically having higher seafood consumption rate and a closer relationship with fishmongers, and the latter consuming less seafood and showing greater reliance on processed seafood available in supermarkets (EUMOFA 2017; EUMOFA 2019).

\section{Methods}

\section{Data collection}

We recorded consumers' ability to visually identify common fish species across six countries: Belgium, Ireland, United Kingdom ('Western Europe'), Greece, Italy, and Spain ('Southern Europe'). A total of 720 consumers (120 per country) were interviewed in general retail areas of the city centers of Ostend, Dublin, Manchester, Thessaloniki, Turin, and Barcelona, between October and December 2016. City centers were chosen for this study to avoid socio-economic biases linked with certain neighborhoods. Consumers were 
chosen randomly in the crowd and were not purchasing seafood at the time of the interview. A set of six fish species were presented in the form of pictures to the participants and they were asked to identify each species as best they could. As illustrated in Fig. 1a, the photos illustrated the side view of a whole specimen and the species included four major fishery resources of European waters: Atlantic cod (Gadus morhua), Atlantic mackerel (Scomber scombrus), European anchovy (Engraulis encrasicolus), and Common sole (Solea solea), and the two top mariculture species produced in Europe: Atlantic salmon (Salmo salar) and European seabass (Dicentrarchus labrax). Correct, incorrect, and void answers were recorded and standardised across countries using official English language denominations. Vernacular versions of fish names and their regional variants across countries (i.e. 'mackerel' for Atlantic mackerel, or the Italian 'branzino' for European seabass) were all accepted as correct responses.

\section{Statistical analysis}

All statistical analyses were performed in R (R Core Team 2019; https://www.r-project.org/). The regional identification accuracy for each individual fish species (i.e. Atlantic cod, Atlantic mackerel, European anchovy, Common sole, Atlantic salmon, and European seabass) presented to consumers was tested using a chi-squared tests. For each species, we expected that identification accuracy differs significantly between WEU and SEU regions. A Cumulative Link Model (clm, also known as Ordinal Logistic Regression) was used to test whether the number of correct answers from participants (0-6) differed significantly between regions. $\mathrm{clm}$ is a powerful non-parametric test well suited for data with ordinal dependent variables such as these. We used the package "ordinal" to generate the model (Christensen 2019). To test whether percentage accuracy of responses differed significantly between countries, we used a non-parametric Kruskal-Wallis test followed by a Dunn post hoc test as our data violated parametric test assumptions. To do so, we used the package "FSA" (Ogle et al. 2020). Given similarity of response between countries of a given region and the observed differences in accuracy between regions, we here extrapolate the results from each city to the country they belong to. For regions, parametric test assumptions were met, permitting us to evaluate the effect of region on percent accuracy of response using a student's $t$ test.

To evaluate how wrong answers for each of the six species differed between regions and countries, we used two diversity indices: species richness $R$, and the Shannon diversity index, $H^{\prime}$. The richness of wrong answers allowed us to quantify the total number of wrong species participants suggested for each country and region, whereas the Shannon diversity index allowed us to account not only for the number of wrong species but also the frequency of each wrong answer. Species richness was calculated as the total number of species wrongly guessed and the Shannon diversity index was calculated using the following formula:

$H^{\prime}=-\sum_{i=1}^{R} p_{i} \ln p_{i}$

where $p_{i}$ is the proportion of wrong answers belonging to the $i$ th species. A one-way ANOVA was used to determine whether the richness and Shannon diversity means differed significantly between regions and countries, and a post hoc Tukey HSD test was performed for pairwise comparison among tested countries. For most graphical representations, the R package "ggpubr" was used (Kassambara 2020) and figures were processed and assembled in Adobe Illustrator (Adobe Inc. 2019). The chord diagrams of the diversity of wrong answers were generated using the Circos software (Krzywinski et al. 2009).

\section{Results and discussion}

\section{Seafood consumption and unfamiliarity with fish appearance}

Consumers' unfamiliarity with the appearance of common fish species was flagrant, with an average of $30.19 \%$ identification accuracy across all countries. A Kruskal-Wallis Test indicated that percentage accuracy of response was significantly different (Chi square $=61.47, p<0.001, d f=5$ ) among the six countries (see Table S1 for KW post hoc Dunn's test), and a $t$ test indicated that region provenance of consumers affects the percent accuracy of their response $[t(718)=5.26$, $p<0.001]$. Western European (WEU) countries did relatively worse, with the United Kingdom recording the lowest identification accuracy of $18.19 \%$, followed by Belgium with 26.39\%, while Southern European (SEU) countries performed slightly better on average, with values ranging between $31.81 \%$ (Greece) and 37.50\% (Spain) (Fig. 1a). Significant regional differences in species-specific identification success were also apparent for five out of the six species we presented to consumers. Unsurprisingly, cod and salmon, traditional mainstays of cold temperate waters, accounted for most of the successful identifications in the UK and Ireland (where they are also most consumed, EUMOFA 2017), while warmer-water species such as anchovy, seabass, and sole accounted for most of the successful identifications in Italy and Greece (Fig. 1a), suggesting that identification ability is intricately linked to traditional culinary habits and to the historical availability of species in the countries' waters and markets. 
When countries were separated into Western and Southern clusters, based on the EU Commission map (EUMOFA 2017), consumers from Southern EU countries revealed finer identification skills than consumers from Western EU countries. The ordinal regression analysis indicated that regions differed significantly from each other in terms of the number of correct answers $(\mathrm{z}=-5.21, p<0.001$ see Table S2 for threshold coefficients) and overall, greater identification accuracy can also be seen in the distributions of probabilities in Fig. 1b. Although regional discrepancies had previously been highlighted in terms of mislabeling rate and consumer awareness (Miller et al. 2012a; Bréchon et al. 2016), which likely arise from the interplay of several cultural, demographic, and regulatory differences, the extent and implications of seafood literacy in the population had up to this point been largely neglected. Seafood consumption habits differ greatly among the countries investigated (Bruns $\varnothing$ et al. 2003; EUMOFA 2017; EUMOFA 2019), which also may affect fish species recognition performance. Spanish respondents demonstrated the highest level of identification success, and over $85 \%$ indicated that they consumed seafood at least once a month, a rate higher than in any other surveyed country (Fig. 2a) and consistent with previously reported data (EUMOFA 2017). The UK and Greece on the other hand currently have the lowest per capita consumption of seafood among the six countries, which was reflected in the responses to our survey (Fig. 2a); yet, identification accuracy in Greece is significantly higher than in the UK (Kruskal-Wallis post hoc Dunn's test $p<0.001$, Table S1), likely due to the intersection of another factor: the way fish is traditionally presented to the consumer at retail level. SEU citizens are typically exposed to a greater diversity of species, displayed whole in most food stalls (Fig. 2b), which has arguably led to greater familiarity with the appearance of fishes in southern countries, while WEU fish markets generally offer a relatively narrow range of species, often already filleted (Fig. 2c).

The trends illustrated above likely represent cultural and market-based legacies of a recent past where seafood supply chains were less globalised (see Miller et al. 2012b for a case study). More recently, the appetite for fast and easy to prepare meals (EUMOFA 2019), especially among urbandwelling younger generations (Brunsø et al. 2009), is partly responsible for motivating the retail sector to prioritize processed products over fresh ones, favoring supermarkets to the detriment of fishmongers. Between 1988 and 1995, the largest retail chains in the United Kingdom, for instance, have gone from selling $31.5 \%$ to $60.9 \%$ of all the fresh fish

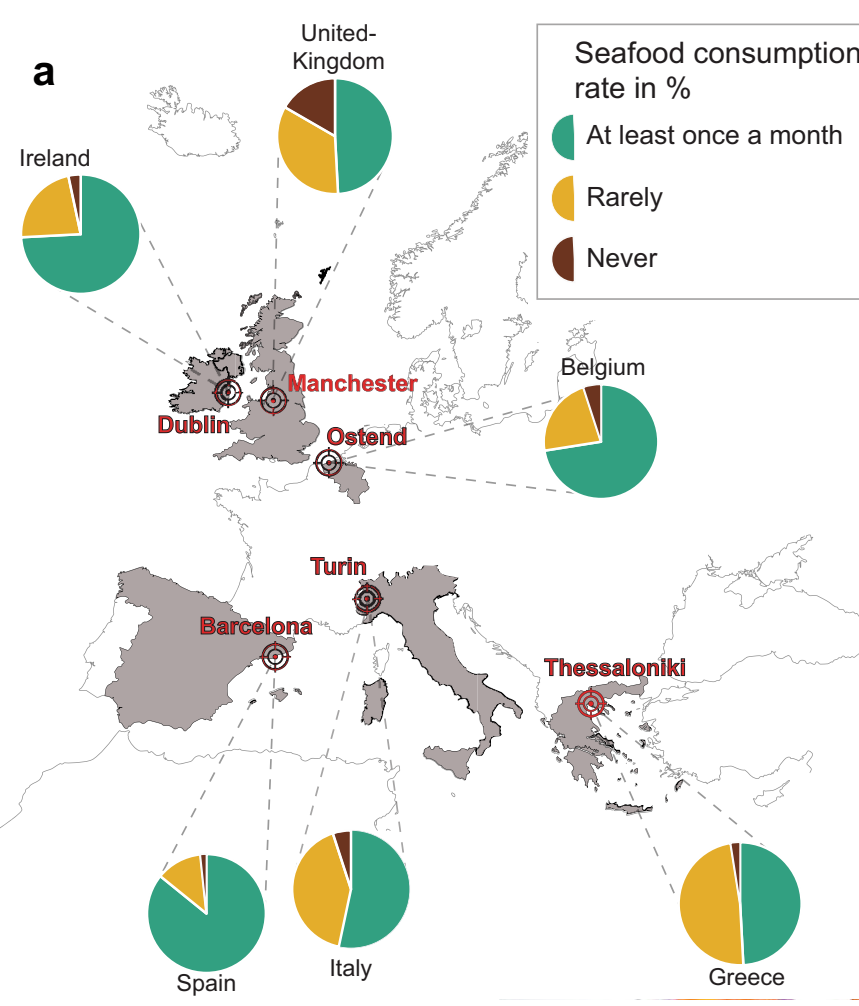

Fig. 2 a Seafood consumption rate in percentage for a total of 720 participants from six European countries. b An example of a Mediterranean seafood stall (Livorno, Italy); c A northern example (Hereford,
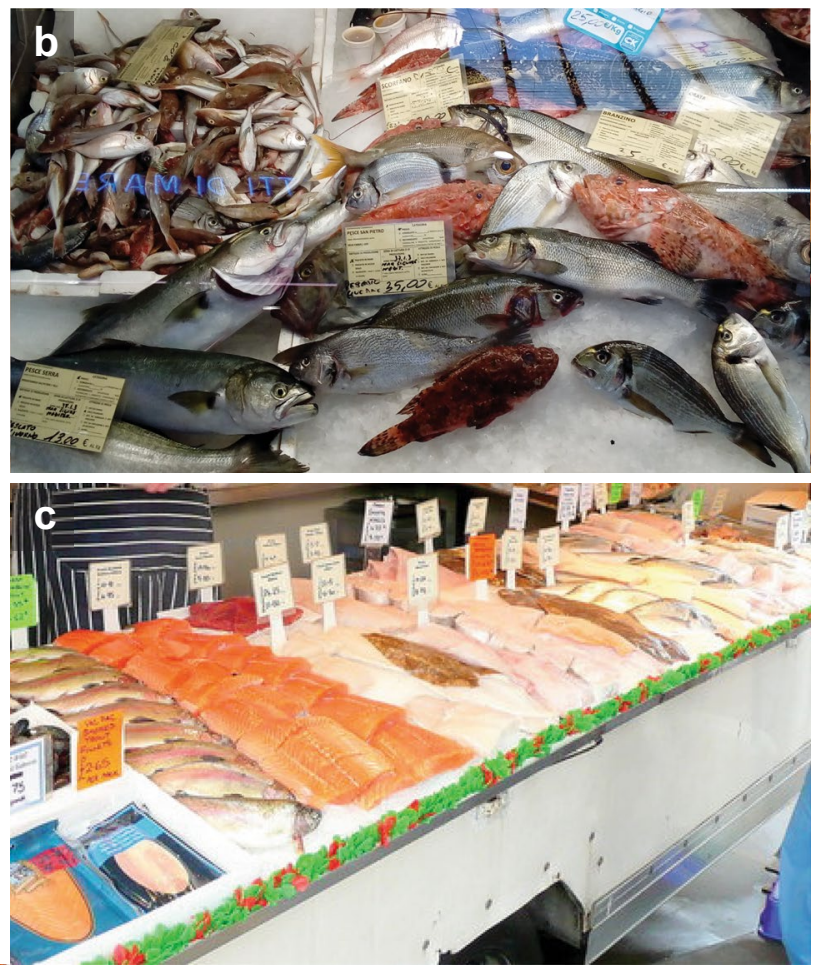

UK), these pictures were not taken in the cities chosen for this study and serve as an illustrative purpose only 
(Murray and Fofana 2002). Fishmongers and supermarkets adopt different product presentation strategies, and whereas fishes are more likely to be laid fresh and whole on a stall in fishmonger stores, they tend to be presented as processed products in shelves or freezers in supermarkets (Murray and Fofana 2002). Packaged and labelled seafood products often contain processed fish that lack morphological characteristics, forcing the consumer to rely on labels for product information, including species identification (De Almeida et al. 1997). The explosive increase of mariculture, which jumped from 5 million tons in 1988 to 31 million tons in 2018 (FAO 2020) also likely contributed to the gradual dilution of regional associations between people and fish in Europe. This is epitomised by Atlantic salmon which jumped from a global production of 38 thousand tons in 1985 to 2 million tons in 2016 (Cultured Aquatic Species Information Programme 2004) and which was the second most consumed fish after tuna and the most consumed farmed species in the EU in 2018 (EUMOFA 2020).

\section{Consumers' perception of seafood}

When asked to identify fish pictures, participants from WEU and SEU countries not only differed in terms of the accuracy of their response but also in terms of the richness and diversity of answers they provided. We harnessed the information contained in the incorrect answers to glean insights into the consumers' perception of the nature and diversity of seafood. An ANOVA indicated that means were significantly different between countries for both species richness $[F(5,30)=11.8, p<0.001]$ and Shannon-Wiener index $[F(5,30)=4.08, p<0.001]$. Mean species richness and mean Shannon-Wiener diversity was also calculated for each region, and an ANOVA indicated that means were significantly different between regions for both species richness $[F(1,34)=17.38, p<0.001]$ and Shannon-Wiener index $[F(1,34)=10.05, p<0.001]$. Post hoc Tukey's HSD tests provided in the Supplementary information (Table S3 and S4) indicated perhaps surprisingly, that participants from Western Europe, the region with the poorest identification accuracy, provided the most rich and diverse answers (Fig. 3).

A closer look at the diversity of answers in each of the two studied regions offers an interesting perspective on consumers' knowledge and perceived fish diversity (Fig. 4a, b). Participants from WEU countries were more prone to take wild guesses, with some answers clearly illustrating a lack of knowledge regarding shape and morphology, such as 'goldfish', 'minnow', 'piranha', 'stickleback', and 'tiger shark' (Fig. 4a). Answers from SEU participants proved more realistic, with most wrong guesses attributed to other frequently consumed species (Fig. 4b). A species by species approach illustrated how these regions are accustomed to different fish species. For example, whereas sole was almost systematically correctly identified in southern countries, with only a few participants labelling it as a different species, more than half of the participants from WEU countries wrongly identified sole as plaice (Pleuronectes platessa) instead, which is the most popular flatfish traditionally caught and served in North-WEU waters (Fig. 4a). In contrast, participants from WEU countries accurately identified salmon more frequently than participants from SEU countries, who disproportionally guessed that salmon and cod were a species of trout (Fig. 4b), most likely due to their habit of consuming
Fig. 3 Line plots illustrating the mean values and standard errors for species richness (in red) and Shannon diversity index (in blue) from the participants' wrong answers for each fish picture (total $=6$ pictures)

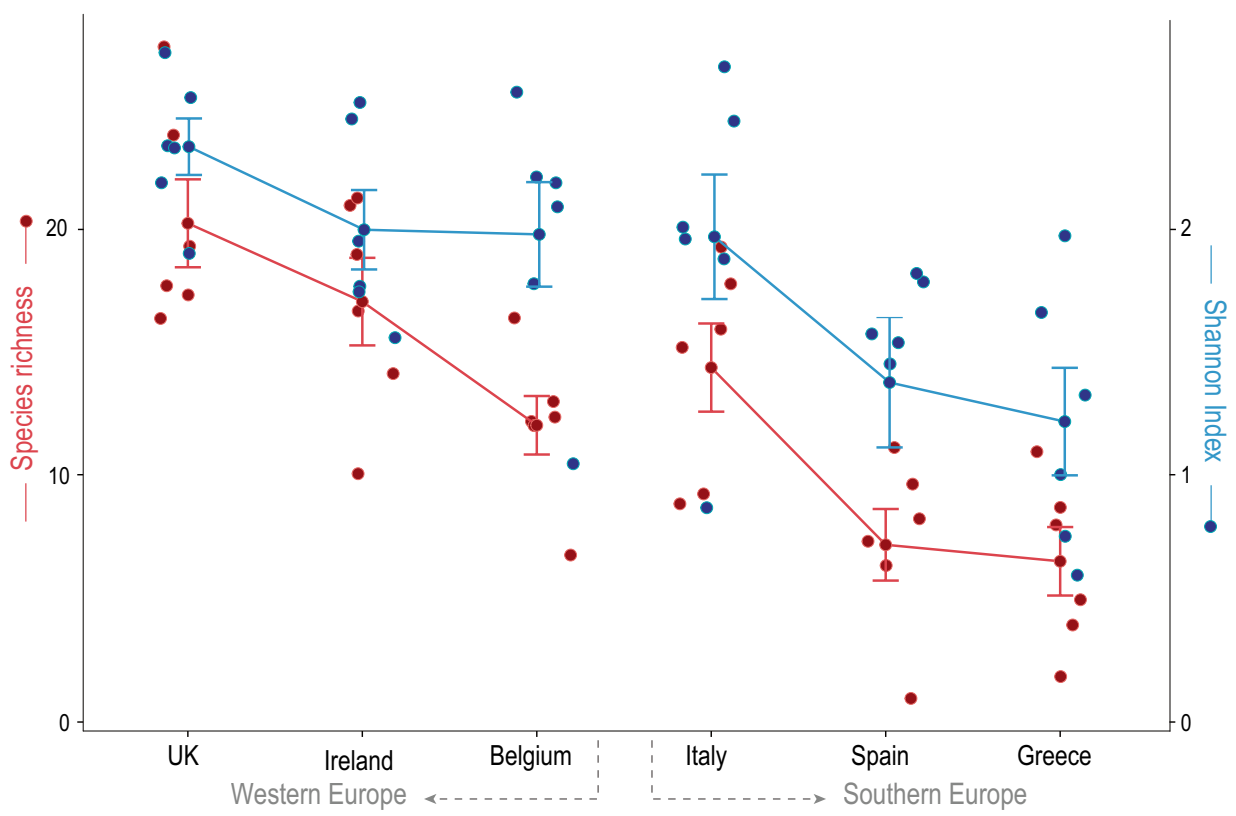


Fig. 4 Diversity of guessed answers by consumers linked to the six species presented to customers in the form of pictures (to the left of the diagram $=$ sole, mackerel, sea bass, anchovy, salmon, and cod).

The bands thickness from the circular diagrams indicate the proportions of answers linked to a given guess. Answers were cumulated for (a) Western European countries (Ireland, United Kingdom, and Belgium) and (b) Southern European countries (Spain, Italy, and Greece). The chord diagram was created using the online Circos software (Krzywinski et al. 2009)
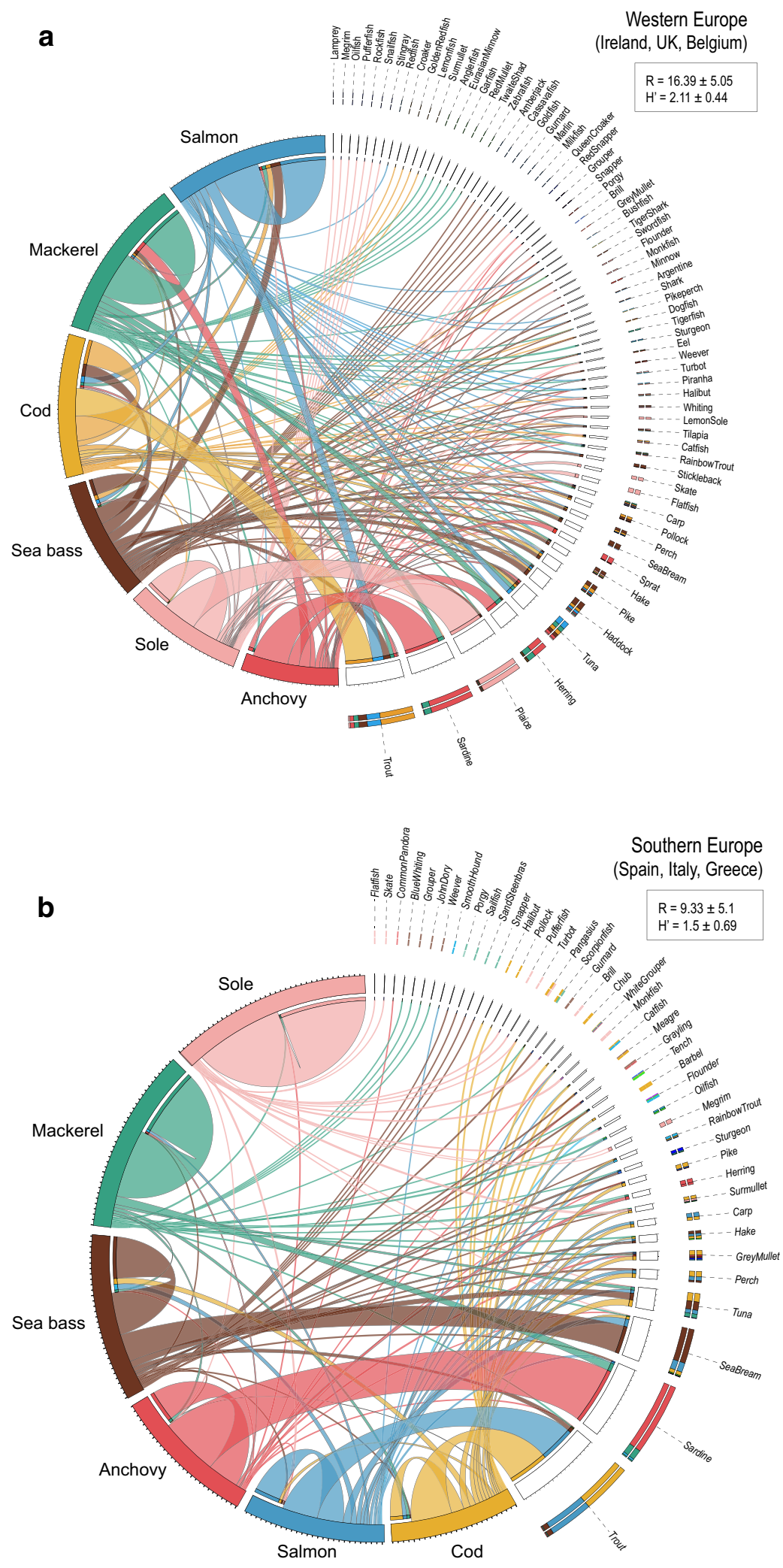
imported cod and salmon in the form of fillets and/or salted and smoked products. Seabass, which only recently became a regular farmed import in North-western Europe, was mistaken for a greater variety of improbable species in WEU countries (Fig. 4a).

More efficient supply chains and urbanisation have dramatically modified seafood culinary cultures around the world (Carroll 2009; Bellotti 2010; Levin and Dufault 2010). In 2018, over $70 \%$ of the European population lived in urban centers (i.e. cities or towns and suburbs) (Eurostat 2020). The 'rural flight' phenomenon has, in part, been made possible by efficient modern supply chains, effectively disconnecting consumers from the source of the food they purchase (Bellotti 2010). Today, food products do not need to be consumed fresh and can be shipped thousands of kilometers from their point of origin, sometimes traveling in convoluted ways before reaching their final destination (e.g. a large proportion of Atlantic cod are caught in Scandinavian waters and in the Barents sea, processed in China, only to find their way back to the European market) (Anderson et al. 2018). That being said, homogenisation of consumption habits is not entirely impermeable to cultural forces (Miller et al. 2012a). Traditional staple foods which often used to be determined by local availabilities carry a strong momentum in guiding contemporary consumer choices (Nestle et al. 1998; Asp 1999). Indeed, both WEU and SEU countries have had in the past and continue to have a significant supply of locally harvested fishery and aquaculture products (EUMOFA 2017) which is highlighted in this study by region-specific abilities to identify commonly consumed fish.

Cultural habits have also led to a sustained demand for specific seafood products, yet with the decline of local fisheries, these demands have become harder to satisfy, leading to the commoditization of seafood, a phenomenon likely affecting consumers ability to discriminate between species. The whitefish market for instance, which was dominated by cod for decades, also comprised other wild caught and farmed species (Asche et al. 2009) ever diluting an already broad category of species, and rendering the 'whitefish' term meaningless to many. Indeed, as indicated by Asche et al. (2009), the whitefish market also comprised other wild caught species such as saithe (Pollachius virens), redfish (Sebastes sp.), haddock (Melanogrammus aeglefinus), pacific cod (Gadus macrocephalus), and Alaska pollock (Gadus chalcogrammus), most of which were deemed less valuable. From the 1990s the whitefish market begun to be substantially inflated by widely traded farmed species, such as catfish (Siluriformes), hoki (Macruronus novaezelandiae), Nile perch (Lates niloticus), and more recently tilapia (Oreochromis sp.) and pangasius (Pangasianodon hypophthalmus) (Asche et al. 2009). In a world where wild caught landings have plateaued and where aquaculture shoulders the growth of the seafood trade, staple species are increasingly becoming replaceable.

With urbanisation comes detachment from the natural world, which likely determines the results we observe. Providing consumers with adequate educational tools such as fish guides and certification schemes is useful for concerned and environmentally aware consumers; but when purchasing seafood, many consumers will often remain more focused on prices and expiry dates rather than on biodiversity (Pieniak et al. 2007). Knowledge, which is a decisive factor when it comes to the types of information consumers will consider while carrying out purchases (Pieniak et al. 2013), is highly heterogenous and will depend on factors such as education level, age, social status, culture, and rate of seafood consumption. For many less informed consumers "fish is simply fish" (Pieniak et al. 2007) and purchasing choices will be centered around quality and safety rather than around species type (Dey et al. 2008). The ability to identify wild species is linked with increased care, interest, and awareness for biodiversity (Schlegel and Rupf 2010; Mohneke et al. 2016), and it should, therefore, come as a concern that the consumers from this study performed so poorly, with an average identification accuracy of $\sim 30 \%$. This comes in sharp contrast with performance on the identification of common native terrestrial species, with an average identification accuracy of $\sim 68 \%$ among the general public in the Netherlands (Hookaas et al. 2019). To view fish products as a homogenised commodity is to overlook any speciesspecific ecological and environmental concerns that pertain to the diverse and complex fisheries industry. Until consumers understand this, seafood will likely continue to be at the mercy of fraudulent practices such as species mislabeling, species substitution, and illegal, unreported, and unregulated fishing. However, additional work is needed to evaluate if mislabeling practices and instances of seafood fraud tend to be higher in countries with lower seafood literacy.

\section{Conclusion}

We provide the first quantitative characterisation of seafood literacy in the largest seafood market in the world, the European Union. Though consumers from urban centers of Southern European countries were generally more successful at identifying fish, the overall trend from this study illustrates consumers' relative unfamiliarity with the appearance of commercial fish species in both Western and Southern European countries. Culinary traditions heavily influence the diversity of answers from the respondents, and the correct identification of species. Nevertheless, despite cultural inertia, modern lifestyles are increasingly detaching consumers from the source of their food. The growing demand for seafood and the dynamic nature of 
the fisheries industry are responsible for the grouping of fish species into broad categories, masking seasonal and yearly variations in species harvest, production, and trade, and offering a constant and steady commodity to the consumer. Globalised supply chains and urbanisation are likely at the core of the low seafood literacy we observe, and of a gradual homogenisation of food cultures among countries. In this context, the low identification accuracy we observe across countries seems predictable, if anything, it is rather surprising that consumers should be able to identify any fish species at all, and it reveals some level of contact with whole specimens despite market trends pushing for processed products.

Increasingly, environmental Non-Governmental Organisations and stakeholders have provided consumers with seafood educational support as an attempt to guide their purchase towards sustainable consumption habits. Despite well-intentioned incentives provided by labelling standards and certification schemes, our results clearly demonstrate a lack of knowledge regarding the appearance of commonly consumed fish. Studies have demonstrated that the ability to identify given species is linked with increased appreciation and respect and can have far reaching consequences in terms of conservation. Though this study does not examine causality between seafood literacy and seafood sustainability, it is nonetheless possible to assume that consumers' inability to identify common fish species might result in a disinterest for sustainable consumption of seafood. We, therefore, suggest that there is a pressing need to continue educating consumers about seafood and we recognize that this responsibility should not solely rest on the shoulders of NGOs. It ought to be addressed by concerted actions involving practicing scientists, governments, and civil society at large, with the view to transform the way modern citizens perceive wild foods. It is not surprising that in the current context, consumers might display a lack of interest and ability in discriminating between species. When it comes to identifying fish species, consumers are like fish out of water.

\section{Ethical approval}

We confirm that informed consent was obtained from all participants involved in this study. We confirm that the project was approved by the University of Salford's ethics committee as a Type 2 project: routine project work involving human/animal subjects/tissue where ethical issues have been considered and appropriately addressed.

Supplementary Information The online version contains supplementary material available at https://doi.org/10.1007/s11625-021-00932-z.
Acknowledgments We thank Ilaria Coscia for help and advice on the study design. This study was supported by Collaborative Agreement 613688 under the EU FP7 KBBE.2013.2.4-01 'Food Integrity' grant, the EU Interreg Atlantic Area Program grant EAPA87/2016 'SEATRACES', and the CAPES Foundation grant, Ministry of Education of Brazil. We thank two anonymous reviewers whose comments and suggestions helped improve this manuscript.

Author contributions MC, LF, JDJ, CB, LB, MB, FB, LD, SG-P, CG, $\mathrm{SM}, \mathrm{KVH}, \mathrm{PLA}$, and SM were involved in collecting data, conceptualizing, writing, reviewing, and editing. SM conceived the study, MC, $\mathrm{LF}$, and SM wrote the original draft and MC conducted the data analysis and created data visualizations. MC and SM coordinated the work.

Data availability Data supporting this article is available on Dryad.

Open Access This article is licensed under a Creative Commons Attribution 4.0 International License, which permits use, sharing, adaptation, distribution and reproduction in any medium or format, as long as you give appropriate credit to the original author(s) and the source, provide a link to the Creative Commons licence, and indicate if changes were made. The images or other third party material in this article are included in the article's Creative Commons licence, unless indicated otherwise in a credit line to the material. If material is not included in the article's Creative Commons licence and your intended use is not permitted by statutory regulation or exceeds the permitted use, you will need to obtain permission directly from the copyright holder. To view a copy of this licence, visit http://creativecommons.org/licenses/by/4.0/.

\section{References}

Altintzoglou T, Nøstvold BH (2014). Labelling fish products to fulfil Norwegian consumers' needs for information. Br. Food J.

Anderson JL, Asche F, Garlock T (2018) Globalization and commoditization: the transformation of the seafood market. J Commod Markets 12:2-8

Asche FK, Roll H, Trollvik T (2009) New aquaculture species-the whitefish market. Aquacult Econ Manag 13:76-93

Asp EH (1999) Factors affecting food decisions made by individual consumers. Food Policy 24:287-294

Balmford A, Clegg L, Coulson T, Taylor J (2002). Why conservationists should heed

Bellotti B (2010) Food literacy: reconnecting the city with the country. J Agric Sci 22:29

Bréchon AL, Hanner R, Mariani S (2016) A systematic analysis across north Atlantic countries unveils subtleties in cod product labelling. Mar Policy 69:124-133

Brunsø K (2003). Consumer research on fish in Europe. In quality of fish from catch to consumer: labelling, monitoring and traceability (pp. 335-344). Wageningen Academic Publishers.

Bruns $\varnothing$ K, Verbeke W, Ottar Olsen S, Fruensgaard Jeppesen L (2009) Motives, barriers and quality evaluation in fish consumption situations. Brit Food J 111:699-716

Calosso MC, Claydon JA, Mariani S, Cawthorn DM (2020) Global footprint of mislabelled seafood on a small island nation. Biol Conserv 245:108557

Carroll WF (2009) Sushi: globalization through food culture: towards a study of global food networks. J East Asian Cult Inter Stud 2:451-456

Cawthorn DM, Mariani S (2017) Global trade statistics lack granularity to inform traceability and management of diverse and high-value fishes. Sci rep 7:1-11 
Cawthorn DM, Baillie C, Mariani S (2018) Generic names and mislabeling conceal high species diversity in global fisheries markets. Conserv Lett 11:e12573

Christensen RHB (2019). Ordinal-regression models for ordinal data. R package version 2019.12-10. https://CRAN.R-project.org/packa ge $=$ ordinal

Cohen A (1997) Sturgeon poaching and black market caviar: a case study. Environ Biol Fishes 48:423-426

De Almeida MDV, Graca P, Lappalainen RETAL, Giachetti I, Kafatos A, Remaut de Winter AM, Kearney JM (1997) Sources used and trusted by nationally-representative adults in the European Union for information on healthy eating. Eur J Clin Nutr 51:16-22

Dey MM, Garcia YT, Praduman K, Piumsombun S, Haque MS, Li L, Koeshendrajana S (2008) Demand for fish in Asia: a cross-country analysis. Aust J Agr Resour Ec 52:321-338

Donlan CJ, Luque GM (2019) Exploring the causes of seafood fraud: a meta-analysis on mislabeling and price. Marine Policy 100:258 264. https://doi.org/10.1016/j.marpol.2018.11.022

EUMOFA (2017). EU consumer habits regarding fishery and aquaculture products. [Accessed June 2020 on https://www.eumofa.eu/ documents/20178/84590/EU+consumer+habits_final+repor t+.pdf/5c61348d-a69c-449e-a606-f5615a3a7e4c]

EUMOFA. (2019). The EU fish market. [Accessed June 2020 on https://www.eumofa.eu/documents/20178/314856/EN_ The+EU+fish+market_2019.pdf/]

EUMOFA (2020). The EU fish market. [Accessed February 2021 on

Eurostat. (2020). [Accessed 23 June 2020 on https://ec.europ a.eu/eurostat/web/products-euros tat-news/-/EDN-20200 207-1\#: : text=In\%202018\%2C\%2039.3\%25\%20of\%20the ,29.1\%25\%20lived\%20in\%20rural\%20areas.]

FAO. (2017). Fisheries and aquaculture software. FishStat Plus - Universal software for fishery statistical time series. In: FAO Fisheries and Aquaculture Department [online]. Rome. Updated 14 September 2017. [Accessed 28 April 2020 on http://www.fao.org/fishery/ statistics/software/fishstat/en].

FAO. (2020). The state of world fisheries and aquaculture 2020. Sustainability in action. Rome. [Accessed June 2020 on https://doi. org/10.4060/ca9229en]

Fields AT, Fischer GA, Shea SKH, Zhang H, Feldheim KA, Chapman DD (2020) DNA Zip-coding: identifying the source populations supplying the international trade of a critically endangered coastal shark. Conserv Anim. https://doi.org/10.1111/acv.12585

Gaviglio A, Demartini E, Mauracher C, Pirani A (2014) Consumer perception of different species and presentation forms of fish: an empirical analysis in Italy. Food Qual Prefer 36:33-49

Griffiths AM, Miller DD, Egan A, Fox J, Greenfield A, Mariani S (2013) DNA barcoding unveils skate (Chondrichthyes: Rajidae) species diversity in 'ray' products sold across Ireland and the UK. PeerJ 1:e129

Hooykaas MJ, Schilthuizen M, Aten C, Hemelaar EM, Albers CJ, Smeets I (2019) Identification skills in biodiversity professionals and laypeople: a gap in species literacy. Biol Conserv 238:108202

https://www.eumofa.eu/documents/20178/415635/EN_ The+EU+fish+market_2020.pdf/fe6285bb-5446-ac1a-e213-6fd6f $64 \mathrm{~d} 0 \mathrm{~d} 85 ? \mathrm{t}=1604671147068]$

Adobe Inc. 2019. Adobe Illustrator Available at: https://adobe.com/ products/illustrator

Jacquet JL, Pauly D (2007) The rise of seafood awareness campaigns in an era of collapsing fisheries. Mar Policy 31:308-313

Kassambara A (2020). ggpubr: 'ggplot2' based publication ready plots. R package version 0.2.5. https://CRAN.R-project.org/packa ge $=$ ggpubr

Kroetz K, Luque GM, Gephart JA, Jardine SL, Lee P, Moore KC, Donlan CJ (2020) Consequences of seafood mislabeling for marine populations and fisheries management. PNAS 117:30318-30323
Krzywinski M et al (2009) Circos: an information aesthetic for comparative genomics. Genome Res 19:1639-1645

Levin PS, Dufault A (2010) Eating up the food web. Fish Fish 11:307-312

Mariani S, Ellis J, O'Reilly A, Bréchon AL, Sacchi C, Miller DD (2014) Mass media influence and the regulation of illegal practices in the seafood market. Conserv Lett 7:478-483

Mariani S, Griffiths AM, Velasco A, Kappel K, Jérôme M, Perez-Martin RI, Boufana B (2015) Low mislabeling rates indicate marked improvements in European seafood market operations. Front Ecol Environ 13:536-540

Miller DD, Clarke M, Mariani S (2012) Mismatch between fish landings and market trends: a Western European case study. Fish Res 121:104-114

Miller D, Jessel A, Mariani S (2012) Seafood mislabelling: comparisons of two western European case studies assist in defining influencing factors, mechanisms and motives. Fish Fish 13:345-358

Mohneke M, Erguvan F, Schlüter K (2016) Explorative study about knowledge of species in the field of early years education. J Emergent Sci 11:1-234

Murray AD, Fofana A (2002) The changing nature of UK fish retailing. Mar Resour Econ 17:335-339

AdersonAscheGarlock JLFT (2018) Globalization and commoditization: the transformation of the seafood market. J Commod Mark $12: 2-8$

Nestle M, Wing R, Birch L, DiSogra L, Drewnowski A, Middleton $S$, Economos C (1998) Behavioral and social influences on food choice. Nutr Rev 56:S50-S74

Ogle DH, Wheeler P, Dinno A (2020). FSA: fisheries stock analysis. R package version 0.8.30, https://github.com/droglenc/FSA

Olson J, Clay PM, da Silva PP (2014) Putting the seafood in sustainable food systems. Mar Policy 43:104-111

Perry EA, Thomas H, Samra HR, Edmonstone S, Davidson L, Faulkner A, Kirkpatrick SI (2017) Identifying attributes of food literacy: a scoping review. Public Health Nutr 20:2406-2415

Pieniak Z, Verbeke W, Vermeir I, Bruns $\varnothing$ K, Olsen SO (2007) Consumer interest in fish information and labelling. J Int Food Agribusiness Mark 19:117-141

Pieniak Z, Vanhonacker F, Verbeke W (2013) Consumer knowledge and use of information about fish and aquaculture. Food Policy 40:25-30

Pokémon. Science. 295, 2367

Cultured aquatic species information Programme. Salmo salar. Cultured aquatic species information programme. Text by Jones M In: FAO fisheries division [online]. Rome. Updated 1 January 2004. [Cited 10 December 2020]

R Core Team (2019). R: A language and environment for statistical computing. R Foundation for Statistical Computing, Vienna, Austria. URL https://www.R-project.org/

Rodriguez-Salvador B, Dopico DC (2020) Understanding the value of traceability of fishery products from a consumer perspective. Food Control 112:107142

Schlegel J, Rupf R (2010) Attitudes towards potential animal flagship species in nature conservation: a survey among students of different educational institutions. J Nat Conserv 18:278-290

Vidgen HA, Gallegos D (2014) Defining food literacy and its components. Appetite 76:50-59

Vileisis A (2008) Kitchen literacy: how we lost knowledge of where food comes from and why we need to get it back. Island Press, Washington, DC

Vitale S, Biondo F, Giosuè C, Bono G, Okpala COR, Piazza I, Pipitone $\mathrm{V}$ (2020) Consumers' perception and willingness to pay for ecolabeled seafood in Italian hypermarkets. Sustainability 12:1434

Publisher's Note Springer Nature remains neutral with regard to jurisdictional claims in published maps and institutional affiliations. 